\title{
Prevalence of silent myocardial ischemia in working-age patients with type 2 diabetes mellitus
}

\author{
Alexander Kiško', Marika Vereb², Radoslav Dobránsky³, Marian Babčák', \\ Lubica Derňarová', Jan Kmec', Jozef Leško ${ }^{4}$, František Neméth', \\ Maria Marcinkovás, Zuzana Farkašovál
}

I University in Prešov, Faculty of Health Care; Cardiology Clinic, ProCare Prešov, Prešov, Jurkovičova 19. 0800I Prešov, Slovak Republic.

${ }^{2}$ Institute of Nuclear Medicine, Klinikum Kassel, Klinikum Kassel. D-34I25 Kassel, Germany.

${ }^{3}$ Diabetic \& Metabolic Disorders Clinic, ProCare Prešov, Jurkovičova 19. 0800I Prešov, Slovak Republic.

${ }^{4}$ VIVAMED Itd, Nuclear Medicine, Hollého 14. 08I8I Prešov, Slovak Republic.

${ }^{5}$ Cardiology Clinic, ProCare Prešov, Jurkovičova 19. 0800I Prešov, Slovak Republic. alexander.kisko@unipo.sk; mudr.marika.vereb.@gmail.com; dobranskyrado@gmail.com; babcak@fnsppresov.sk; lubica.dernarova@unipo.sk; kmecj@fnsppresov.sk; lesko@vivamed.sk; frantisek.nemeth@unipo.sk; marcinkova8@gmail.com; zuzana.farkasova@unipo.sk

\section{Abstract}

Introduction: Data confirm a relatively high prevalence of silent myocardial ischemia (SMI) in elderly patients with type 2 diabetes mellitus (T2DM), while no data are available regarding working-age subjects ( $\leq 60$ years). Methods: Medical records of 192 patients with $\mathrm{T}_{2} \mathrm{DM}$ aged $\leq 60$ years (110 male patients; $57.3 \%$ ), who had undergone myocardial perfusion imaging (MPI) between 2010 and 2014 followed by coronary angiography in case of abnormal result, were retrospectively analysed. Results: MPI was positive in 35 patients (18.2\%); of those 31 (88.6\%) had angiographically confirmed coronary stenosis. The positive predictive value of the MPI for predicting angiographic coronary stenosis in this age subgroup was $88.9 \%$. Univariate analysis revealed post-stress LVEF drop $\geq 5 \%(\mathrm{p}<0.03)$ and NT-proBNP levels detected in stress $(\mathrm{p}<0.05)$ to be associated with greater risk of ischemia in workingage $\mathrm{T}_{2} \mathrm{DM}$ patients. In multivariate analysis, LVEF drop $\geq 5 \%(\mathrm{p}<0.03)$ remained an independent predictor of SMI.

Conclusion: Prevalence of SMI in diabetic working-age patients was similar to that observed in studies of subjects over 65 years-old. Poststress LVEF drop $\geq 5 \%$ and NT-proBNP levels can contribute to more precise identification of SMI. Our data suggest that "aggressive" management strategy should be implemented to reduce the risk of cardiac events in $\mathrm{T}_{2} \mathrm{DM}$ patients of working-age.

Keywords: scintigraphy, silent myocardial ischemia, diabetes mellitus 
yocardial ischemia is often asymptomatic in patients with type 2 diabetes mellitus ( $\left.\mathrm{T}_{2} \mathrm{DM}\right)$ and coronary artery disease (CAD) is frequently in an advanced stage when it becomes clinically manifested. Silent myocardial ischemia (SMI) is defined as objective evidence of myocardial ischemia in the absence of typical chest discomfort or other anginal equivalents. It is a common, under-recognized marker of a significant underlying CAD associated with future cardiovascular events and poor prognosis. SMI is an important public health issue, and its early detection may prevent many episodes of sudden cardiac death annually (Cosson et al., 2005; Le Feuvre et al., 2011; Vasiliadis et al., 2014). Diabetic patients have a higher prevalence of SMI and recognised myocardial infarction than patients without diabetes (MacDonald et al., 2014). There are some data about the prevalence of SMI in T2DM patients in elderly at high risk for cardiovascular disease (Inoguchi et al., 2000; Faglia et al., 2002; Lima et al., 2004; Mohagheghie et al., 2011; Rawshani et al., 2017). However, data about the prevalence of SMI in working-age subgroup of the diabetic population remain limited.

Stress single-photon emission computed tomography (SPECT) is a validated imaging tool providing information on the physiological significance of flow-limitation and is also a cost-effective for risk assessment of the major adverse cardiac events in the general and diabetic populations. SPECT could accurately assess both myocardial perfusion and ventricular function in diabetic patients, providing important information for their management and is helpful in these situations (De Keyzer et al., 2011). Moreover, left ventricular (LV) function analysis in SPECT can enhances its prognostic and diagnostic ability, particularly in the prediction of SMI (Sharir et al., 1999). We sought to evaluate the prevalence of SMI detected by SPECT myocardial perfusion imaging (MPI) in association with some less recognised diagnostic predictors of it in $\mathrm{T}_{2} \mathrm{DM}$ asymptomatic patients of working-age.

\section{Methods}

We retrospectively analysed medical records of 192 (110 male pts; 57.3\%) chronologically consecutive asymptomatic working-age ( $\leq 60$ years) patients with T2DM, who had undergone MPI subsequently followed by coronary angiography in case perfusion abnormalities were found. MPI was performed from 2010 to 2014 at a single outpatient care centre with nuclear medicine unit, according to the EANM procedural guidelines for stress-rest ECG gated SPECT one-day protocol using 99mTc-tetrofosmin (Verberne et al., 2015). Perfusion images were judged blindly by two specialists independently using the 17-segment ASNC model, and SMI was diagnosed consensually as myocardial perfusion abnormalities without associated symptoms. Stress (cycle ergometry) and rest myocardial perfusion abnormalities were described as reversible (ischemia), fixed (scar), or mixed (scar and ischemia). The summed stress score (SSS) and summed rest score (SRS) were obtained, with the summed difference score (SDS) being the difference between the two. A mild ischemic defect was 
defined as showing the presence of a $S D S \geq 2$. A moderate perfusion defect was defined as a SDS $\geq 2$ in $>1$ segment, and severe perfusion defect was defined as a SDS $\geq 3$ in $>1$ segment in stress images. Calculation of left ventricular ejection fraction (LVEF) and ventricular volumes was performed by using quantitative software for endocardial and epicardial boundaries automatically tracing. Patients with abnormal MPI were referred for coronary angiography. Angiographic images were assessed blindly to the MPI data and significant stenosis was defined as $\geq 50 \%$ for LAD, and $\geq 75 \%$ for other coronary arteries.

LV dysfunction was defined as post-stress LVEF drop $\geq 5 \%$ and/or transient ischemic dilatation of LV in stress against rest. The levels of NT-proBNP were measured at rest and within 3 minutes in the early recovery stage of exercise testing.

All participants gave written informed consent before enrolment in the study, which was conducted in accord with the principles of the Declaration of Helsinki. All patients were carefully assessed for classic coronary risk factors: age, sex, obesity, smoking, essential hypertension, dyslipidaemia, a family history of CAD, duration of diabetes, diabetic complications (Table 1).

\section{Table 1: Clinical and laboratory characteristics of the subjects included in the study.}

\begin{tabular}{lc}
\multicolumn{1}{c}{ Clinical and laboratory characteristics } & Diabetic patients $(n=192)$ \\
Age (years) & $52.3 \pm 6.7$ \\
\hline Male (n/\%) & $110 / 57.3$ \\
\hline Obesity (n/\%) & $151 / 78.6$ \\
\hline Smoking (n/\%) & $3 / 1.56$ \\
\hline Hypertension (n/\%) & $107 / 55.7$ \\
\hline Dyslipidaemia (n/\%) & $140 / 72.9$ \\
\hline Family history of CAD (n/\%) & $28 / 14.6$ \\
\hline Duration of diabetes (years) & $5.0 \pm 3.2$ \\
\hline Retinopathy (n/\%) & $20 / 10.4$ \\
\hline Nephropathy (n/\%) & $13 / 6.8$ \\
\hline Neuropathy (n/\%) & $7 / 3.6$ \\
\hline Glucose (mmol/l) & $7.8 \pm 2.6$ \\
\hline HbAic $(\%)$ & $7.2 \pm 1.3$ \\
\hline High-sensitivity CRP (mg/l) & $2.2 \pm 2.3$ \\
\hline Total-C (mmol/l) & $6.2 \pm 3.5$ \\
\hline HDL-C (mmol/l) & $0.96 \pm 0.4$ \\
\hline LDL-C (mmol/l) & $4.2 \pm 1.8$ \\
\hline Triglycerides (mmol/l) & $3.9 \pm 2.4$ \\
\hline
\end{tabular}

Note: Data are expressed as the mean $\pm S D$, number and percentage.

Continuous variables were expressed as mean values \pm standard deviation, and frequencies as the number and percentage of patients. Between-group comparisons were made by means of non-parametric Mann-Whitney $U$ test. 
Bivariate associations were tested using $t$ test and Fisher's exact test. To identify the factors independently related with SMI univariate and multivariate analysis was performed. $P$ values of $<0.05$ were considered statistically significant. Statistical analyses were carried out using IBM SPSS Statistics V.19 software.

\section{Results}

MPI results showed that $157(81,8 \%)$ patients had normal myocardial perfusion, while 35 (18.2\%) patients showed perfusion defects on MPI (Table 2). In 33(17.2\%) cases it was defined as reversible and in $2(1.0 \%)$ as mixed.

Table 2: MPI results.

\begin{tabular}{ll} 
Negative (n/\%) & $157 / 81.8$ \\
\hline Positive (n/\%) & $35 / 18.2$ \\
\hline
\end{tabular}

Note: Data are expressed as number and percentage.

$12(33.4 \%)$ out of the 33 reversible perfusion defects were described as mild, $14(42.4 \%)$ - moderate, and 7 (22.2\%) - severe.

$31(88.6 \%)$ patients out of the 35 with abnormal MPI findings represented an abnormal coronary angiography. In 15(48.4\%) out of the 31 patients it was defined as 1 vessel disease, in $10(32.3 \%)-2$ vessels disease and in $6(19.3 \%)-3$ vessels disease. 9 (29.0\%) patients with positive angiographic results represented diffuse disease and vessel occlusion was detected in 2 (6.5\%). Coronary anatomy did not allow any revascularisation procedure in $13(41.9 \%)$ of the patients with abnormal coronary angiography.

These results emphasize the incremental diagnostic value of MPI for evaluation of SMI in this specific subgroup of the diabetic population. MPI have showed a very good degree of specificity of the test (97.6\%) with a positive predictive value of $\mathbf{8 8 . 9 \%}$ for predicting angiographic coronary stenosis (Table3).

Table 3: Evaluation of MPI in predicting angiographic coronary stenosis.

\begin{tabular}{lll}
\multicolumn{1}{c}{ Statistic } & Value & $95 \%$ CI \\
\hline Sensitivity (\%) & 69.5 & $61.5-82.6$ \\
\hline Specificity (\%) & 97.6 & $79.9-99.3$ \\
\hline PPV (\%) & 88.9 & $73.6-95.6$ \\
\hline NPV (\%) & 50.6 & $48.9-52.3$ \\
\hline
\end{tabular}


We observed that retinopathy (OR 2.32; 95\%-CI: 1.05-5.13; p>0.05), nephropathy (OR 2.12; 95\%-CI: 1.o-6.13; p>0.5), and neuropathy (OR 1.70; 95\%CI, 1.07-2.71; $\mathrm{p}>0.05)$ were not associated with abnormal MPI.

Post-stress LVEF drop $\geq 5 \%$ was observed in 32 (91.4\%) patients out of the 35 with abnormal MPI findings. In 29(82.9\%) cases it was associated with poststress transient ischemic dilatation of LV. Patients with LVEF drop $\geq 5 \%$ had higher SDS $(\mathrm{p}<0.01)$, but no significant difference in rest LV values $(\mathrm{p}>0.05)$ compared to patients without perfusion defects.

There was no significant difference between mean rest NT-proBNP lev-

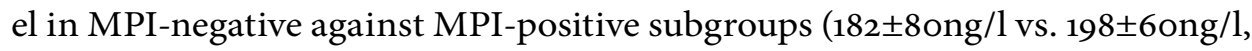
$\mathrm{p}>0.5$ ), but patients with SMI had a significantly higher mean post-stress

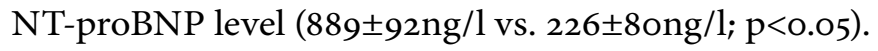

Univariate analysis revealed post-stress LVEF drop $\geq 5 \%(\mathrm{p}<0.03)$ and NT-proBNP level detected in early recovery stage of stress testing $(\mathrm{p}<0.05)$ to be associated with greater risk of ischemia in working-age T2DM pts. In multivariate analysis, LVEF drop $\geq 5 \%(\mathrm{p}<0.03)$ remained to be an independent predictor of SMI.

\section{Discussion}

T2DM is a chronic metabolic disease, which results not only in significant direct medical costs but also in indirect productivity losses due to disability and early mortality in working age population. Almost $75 \%$ of diabetic decedents without clinical CAD have high-grade coronary atherosclerosis. Autopsy studies have identified a high prevalence of coronary atherosclerosis in patients with diabetes, even among those without clinical CAD (Goraya et al., 2002). The prevalence of SMI in the diabetic population is very variable in the different studies, ranging from $12 \%$ to almost $57 \%$, and it is 3 to 6 fold higher than in asymptomatic non-diabetic population (Inoguchi et al., 2000; Wackers et al., 2004; Freeman, 2006; Le Feuvre et al., 2011). Several mechanisms are integrated in the SMI genesis. Endothelial dysfunction secondary to T2DM may play a role, leading to an inappropriate coronary flow response to increasing myocardial metabolic needs (coronary vascular tone abnormality). It is also due to an increased pain feeling threshold in diabetic patients, probably secondary to an elevated beta-endorphins rate. These two abnormalities are associated with an impaired autonomic nervous system.

The patients enrolled in the study were truly asymptomatic, working-age subjects with T2DM, free from known CAD. There were not typical clinical signs of angina at the time of referring patients for MPI. The patients were referred mostly from the clinics for diabetes and metabolic disorders or internal diseases. They were on contemporary medical treatment and were under reasonable metabolic control. Yet, 35 patients (18.2\%) had evidence of SMI, including 21 with moderate-to-severe reversible perfusion abnormalities and 30 with stress-induced ST-segment changes. The prevalence of perfusion abnormalities 
in our study was somewhat lower than the $22 \%$ observed in the DIAD study (Wackers et al., 2004) but a bit greater than $15,7 \%$ obtained in an earlier study from France (Janand-Delenne et al., 1999). However, the lower prevalence reported in this earlier study likely reflects differences in patients selection. Subjects were of younger age, with $\mathrm{T}_{1} \mathrm{DM}$ and $\mathrm{T}_{2} \mathrm{DM}$ and perfusion abnormalities were assessed visually with somewhat less sensitive technique. Moreover, imagings were performed only if the initial exercise ECG stress test was abnormal or equivocal. Thus, patients who would have had perfusion abnormalities were likely missed. On the other hand, it should be noted that the prevalence of perfusion abnormalities in DIAD study is considerably higher than that reported in our study, reflecting the results of adenosine perfusion imaging in a slightly older sample of patients (50-75years).

In a recent study of silent CAD detection in a cohort of 102 asymptomatic T2DM subjects (57士7years), attending 5 Italian outpatient clinics, a significant higher prevalence of silent $\mathrm{CAD}$ was observed in subjects with abnormal vs. normal ECG (23 vs. $4 \%$; $\mathrm{P}=0.004$ ), but not in subjects with high vs. low pretest silent CAD risk (14 vs. $9 \%$; $=0.472$ ). An abnormal ECG was defined to be a strong, independent predictor of silent CAD (OR 8.9; CI 1.27-62.5; $\mathrm{p}=0.028)$ in T2DM (Vigili de Kreutzenberg et al., 2017).

Our second goal was to identify predictors of MPI abnormalities. Demographics, traditional cardiac risk factors, diabetes complications, and biomarkers were analysed. Overall predictors of SMI in working-age cohort of $\mathrm{T}_{2} \mathrm{DM}$ patients were post-stress LVEF drop $\geq 5 \%$ and NT-proBNP levels detected in stress. In univariate analysis, only post-stress LVEF drop $\geq 5 \%$ was the factor associated with moderate-to-large perfusion defects abnormalities that raise substantial clinical concern. In working-age patients with diabetes, post-stress LVEF drop showed to be an independent predictor of stress-induced ischemia and increases the risk of subsequent cardiac events in T2DM patients. However, a fall in LVEF is detectable also in patients with normal myocardial perfusion. These findings suggest that a post-stress LVEF drop may be related to a specific diabetic cardiomyopathy in the absence of myocardial perfusion abnormalities. Diabetic complications such as retinopathy, nephropathy and neuropathy showed not to be significantly associated with either test abnormality or marked perfusion defects. In addition, traditional cardiac risk factors (male gender, hypertension, smoking and family history, or dyslipidaemia), previously reported as risk factors for CAD and poor outcome (De Keyzer et al., 2011) were not associated with SMI in working-age $\mathrm{T}_{2} \mathrm{DM}$ patients.

\section{Conclusions}

Prevalence of $\mathrm{T}_{2} \mathrm{DM}$ in working-age population is high and still rising in Europe. Both diabetes and pre-diabetic states are risk factors for CAD. Their emergence starts many years before clinical events appear, developing silently, in parallel with the progression from pre-diabetic status to T2DM (Alegria-Barrero, 2014). Our study suggests that $18.2 \%$ of asymptomatic working-age pa- 
tients with T2DM have SMI. More importantly, $13.7 \%$ of them have markedly abnormal (moderate-to-severe) myocardial perfusion abnormalities. This justifies screening for SMI by non-invasive and cost-effective technique such as SPECT MPI in subpopulation of T2DM patients of the working-age. LV function testing may have an important role in the SMI risk assessment because of the association shown in the present study between LVEF drop $\geq 5 \%$, NT-proBNP levels detected in stress and perfusion defects occurring. The presented data address only the prevalence, severity, and possible predictors of SMI at the time of enrolment into the study and suggest that advanced intervention procedures including "aggressive" drug management should be implemented to reduce the risk of cardiac events in forthcoming future. Follow-up evaluation should allow to define the relationship between abnormal perfusion imaging and the prevalence of cardiac events in asymptomatic T2DM patients of working-age and to evaluate the effectiveness of "aggressive" preventive strategies.

\section{Acknowledgment}

This study was supported in part by a grant from KEGA (Cultural and Educational Granting Agency) 066PU-4/2016, Ministry of Education, Science, Research and Sports of the SR. The research was designed, conducted, analysed, and interpreted by the authors entirely independently of the funding source.

\section{References}

ALEGRIA-BARRERO, A., 2014. New insights regarding management of diabetes. An article from the E-journal of the ESC Council for Cardiology Practice, vol. 12, no. 11. Available from: https://www.escardio.org/ Journals/E-Journal-of-Cardiology-Practice/Volume-12/New-insights-regarding-management-of-diabetes

COSSON, E., ATTALI, J.R. and VALENSI, P., 2005. Markers for silent myocardial ischemia in diabetes. Are they helpful? Diabetes Metab., vol. 31, no. 2, pp.205-213.

DE KEYZER, E., KERKHOVE, D., VAN CAMP, G., DE SUTTER, J., ACHTERGAEL, W., KEYMEULEN, B. and WEYTJENS, C., 2011. Screening for silent myocardial ischaemia in patients with type 2 diabetes mellitus: a quest to improve selection of the target screening population. Acta Cardiol., vol. 66, no. 6, pp. 715-720.

FAGLiA, E., FAVAlES, F., CALIA, P., PALEARI, F., SEGALINI, G., GAMBA, P.L., ROCCA, A., MUSACCHIO, N., MASTROPASQUA, A., TESTORI, G., et al., 2002. Milan Study on Atherosclerosis and Diabetes (Mi SAD). Cardiac events in 735 type 2 diabetic patients who underwent screening for unknown asymptomatic coronary heart disease: 5-year follow-up report from the Milan Study on Atherosclerosis and Diabetes (MiSAD). Diabetes Care, vol. 25, no. 11, pp. 2032-2036. 
FREEMAN, M., 2006. Myocardial perfusion imaging in diabetes mellitus. Can J Cardiol., vol.22, suppl. A, pp. 22-25.

GORAYA, T.Y., LEIBSON, C.L., PALUMBO, P.J., WESTON, S.A., KILLIAN, J.M., PFEIFER, E.A., JACOBSEN, S.J., FRYE, R.L. and ROGER, V.L., 2002. Coronary atherosclerosis in diabetes mellitus: a population-based autopsy study. J Am Coll Cardiol., vol. 40, no. 5, pp. 946-953.

JANAND-DELENNE, B., SAVIN, B., HABIB, G., BORY, M., VAGUE, P. and LASSMANN-VAGUE, V., 1999. Silent myocardial ischemia in patients with diabetes: who to screen. Diabetes Care, vol. 22, no. 9, pp. 1396-140o.

INOGUCHI, T., YAMASHITA, T., UMEDA, F., MIHARA, H., NAKAGAKI, O., TAKADA, K., KAWANO, T., MURAO, H., DOI, T. and NAWATA, H., 200o. High incidence of silent myocardial ischemia in elderly patients with non insulin-dependent diabetes mellitus. Diabetes Res Clin Pract., vol. 47, no. 1, pp. 37-44.

LE FEUVRE, C., JACQUEMINET, S. and BARTHELEMY O., 2011. Myocardial ischemia: a silent epidemic in Type 2 diabetes patients. Future Cardiol., vol. 7, no. 2, pp. 183-19o.

LIMA, R.S., DE LORENZO, A., PANTOJA, M.R. and SIQUEIRA, A., 2004. Incremental Prognostic value of myocardial perfusion 99m-technetium-sestamibi SPECT in the elderly. Int J Cardiol., vol. 93, no. 2-3, pp. 137-143.

MACDONALD, M.R., PETRIE, M.C., HOME, P.D., KOMAJDA, M., JONES, N.P., BECK-NIELSEN, H., GOMIS, R., HANEFELD, M., POCOCK, S.J., CURTIS, P.S., et al., 2011. Incidence and prevalence of unrecognized myocardial infarction in people with diabetes: a substudy of the Rosiglitazone Evaluated for Cardiac Outcomes and Regulation of Glycemia in Diabetes (RECORD) study. Diabetes Care, vol.34, no. 6, pp. 1394-1396.

MOHAGHEGHIE, A., AHMADABADI, M.N., HEDAYAT, D.K., POURBEHI, M.R. and ASSADI, M., 2011. Myocardial perfusion imaging using technetium-99m sestamibi in asymptomatic diabetic patients. Nuklearmedicine, vol. 50, no. 1, pp. 3-8.

RAWSHANI, A., FRANZÉN, S., ELIASSON, B., SVENSSON, A.M., MIFTARAJ, M., McGUIRE, D.K., SATTAR, N., ROSENGREN, A. and GUDBJÖRNSDOTTIR, S., 2017. Mortality and Cardiovascular Disease in Type 1 and Type 2 Diabetes. N Engl J Med., vol. 13, no. 15, pp. 1407-1418.

SHARIR, T., GERMANO, G., KAVANAGH, P.B., LAI, S., COHEN, I., LEWIN, H.C., FRIEDMAN, J.D., ZELLWEGER, M.J. and BERMAN, D.S., 1999. Incremental prognostic value of post-stress left ventricular ejection fraction and volume by gated myocardial perfusion single photon emission computed tomography. Circulation, vol. 100, no. 10, pp. 1035-1042. 
VASILIADIS, I., KOLOVOU, G., MAVROGENI, S., NAIR, D.R. and MIKHAILIDIS, D.P., 2014. Sudden cardiac death and diabetes mellitus. J Diabetes Complications, vol. 28, no. 4, pp. 573-579.

VERBERNE, H.J., ACAMPA, W., ANAGNOSTOPOULOS, C., BALLINGER, J., BENGEL, F., DE BONDT, P., BUECHEL, R.R., CUOCOLO, A., VAN ECK-SMIT, B.L., FLOTATS, A., et al., 2015. European Association of Nuclear Medicine (EANM). EANM procedural guidelines for radionuclide myocardial perfusion imaging with SPECT and SPECT/CT: 2015 revision. Eur J Nucl Med Mol Imaging, vol. 42, no. 12, pp. 1929-1940.

VIGILI DE KREUTZENBERG, S.,SOLINI, A., VITOLO, E., BOI, A., BACCI, S., COCOZZA, S., NAPPO, R., RIVELlESE, A., AVOGARO, A. and BARONI, M.G., 2017. Silent coronary heart disease in patients with type 2 diabetes: application of a screening approach in a follow-up study. J Diabetes Complications, vol. 32, no. 17, pp. 30111-30113.

WACKERS, F.J., YOUNG L.H., INZUCCHI, S.E., CHYUN, D.A., DAVEY, J.A., BARRETT, E.J., TAILLEFER, R., WITTLIN, S.D., HELLER, G.V., FILIPCHUK, N., et al., 2004. Detection of Ischemia in Asymptomatic Diabetics Investigators. Detection of silent myocardial ischemia in asymptomatic diabetic subjects: the DIAD study. Diabetes Care, vol. 27, no. 8, pp. 1954-1961. 